\title{
Design of Diamond Drill Bits with Primary and Secondary Abrasives
}

\author{
Richeng Zhong ${ }^{1}$, Zhenbin Peng ${ }^{1}$, Haidong Jiang ${ }^{2 *}$ \\ ${ }^{1}$ School of Geoscience and Information Physics, Central South University, Changsha 410083, China \\ ${ }^{2}$ Institute of Resources and Environmental Engineering, Guizhou University of Technology, Guiyang 550003, China
}

Corresponding Author Email: jianghaidong888@163.com

https://doi.org/10.18280/acsm.430307

Received: 3 April 2019

Accepted: 8 June 2019

\section{Keywords: \\ primary and secondary abrasives, impregnated diamond drill bit, micron diamond powder, drilling efficiency, service life}

\begin{abstract}
To improve the drilling efficiency of impregnated diamond drill bit in strong abrasive rock layer, this paper introduces the theory of primary and secondary abrasives into the drill bit design, and explores the drilling efficiency and service life of diamond drill bits with six formulas of primary and secondary abrasives through indoor and field tests. The results show that the drill bits with primary and secondary abrasives had an $85 \%$ higher efficiency and a $46 \%$ longer service life than the conventional drill bit. In the course of drilling, the matrix of the ordinary drill bit was soon worn out due to the repeated grinding by a large amount of medium and coarse rock powder, losing the ability to hold the diamond in place. Then, the drill bit became less durable or efficient. These defects could be overcome by our diamond drill bit design. If applied to strong abrasive formations, the primary and secondary abrasives of our design can crush the medium and coarse rock powder into finer powder. The fine rock power can be discharged timely and rapidly through the bit end via the drilling fluid.
\end{abstract}

\section{INTRODUCTION}

The performance of the drill bit directly determines how effect rock cores can be acquired. In wireline coring, the diamond drill bit must have high drilling efficiency and long service life at the same time. But drilling efficiency and service life of diamond drill bit are often a paradox. Therefore, it has become a research hotspot to achieve efficient drilling with diamond drill bit without shortening its service life. So far, scholars at home and abroad have mainly attempted to improve the drilling efficiency of diamond drill bit from two aspects: the drill bit structure and the matrix formula [1-10].

With the development of manufacturing and material technologies, great progress has been made in optimizing the structure and matrix formula of diamond drill bit. Many innovative methods have emerged for the design and production of conventional diamond drill bit. For example, Cheng [11] developed a laser-welded regularly-spaced diamond drill bit (Figure 1(a)). Xun and Sun [12] designed a regenerative concave non-smooth diamond bit (Figure 1(b)). Brookes [13] created a super-high matrix drill bit with a multilayer nozzle structure, in which the matrix height is $25.4 \mathrm{~mm}$ (Figure 1 (c)). Beijing Institute of Exploration Engineering (BIEE) proposed a two-layer nozzle drill bit (Figure 1(d)). Atlas Copco [14] put forward a drill bit with primary and secondary nozzles, which helps to cool the matrix center and prevent the grooving of matrix crown. Fordia [15] presented the Vulcan series diamond bit (Figure 1(e)) with a 16mm-tall matrix, and tested that the diamond bit reached the service life of 698m. In 2006, Atlas Copco [16] developed the Golden Jet impregnated diamond drill bit, whose matrix height $(16 \mathrm{~mm})$ is taller than that of the conventional drill bit. The BIEE also developed a secondary welded drill bit (Figure 1(f)) with long service life and strong wear resistance, which facilitates the processing of irregular nozzles.

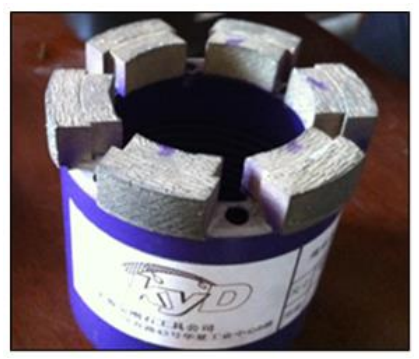

(a) Laser-welded regularly-spaced diamond drill bit

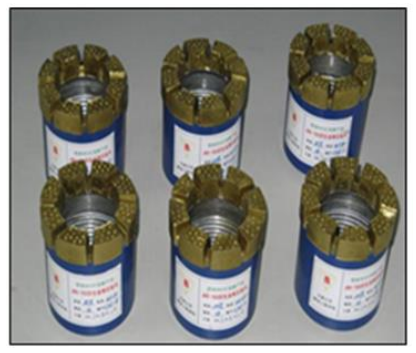

b) Regenerative concave non-smooth diamond bit

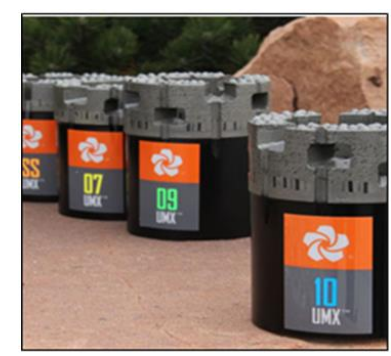

(c) Super-high matrix drill bit with a multi-layer nozzle structure 


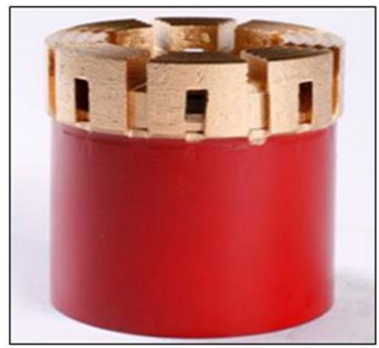

(d) Two-layer nozzle drill bit

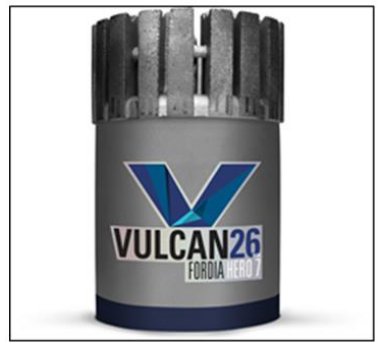

(e) Vulcan series diamond bit

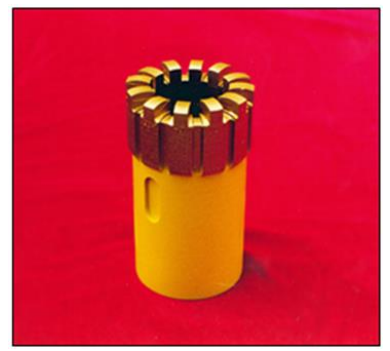

(f) Secondary welded drill bit

Figure 1. New diamond drill bits

Many scholars have resorted to reducing matrix hardness, in order to speed up the wear of matrix and increase the replacement frequency of diamond. In 1995, Umicore [17] pioneered the use of pre-alloyed bond powder (PBP) in diamond tools, and proposed Cobalite HDR, a PBP for drill bit. In 1997, Eurotungstene [18] launched several PBP series, namely, NEXT100, NEXT200, NEXT300 and NEXT900. Dr. Fritsch [19] developed the PBP Diabbase-V21 (Fe, CU, Co and $\mathrm{Sn}$ ) based on Diabbase-V18 (Fe and $\mathrm{Cu}$ ).

In actual applications, the basic or professional PBP is traditionally mixed with elemental powder. The traditional approach is gradually been replaced with the mixing between basic and professional PBPs or PBPs prepared in different methods. In particular, the mixed application of fine PBP and elemental mental powder will be the focus of future development.

Taking $\mathrm{Cu}-\mathrm{Co}-\mathrm{Fe}$ based PBP as the matrix, Villar [20] prepared diamond tools through hot-press sintering, pressureless sintering and isostatic pressing sintering, respectively, and explored the densification of the tools under different process conditions. Thorat et al. [21] investigated how the content and particle size of $\mathrm{Cu}$ affect the sintering properties of $\mathrm{Cu}-\mathrm{Co}-\mathrm{Fe}$ based $\mathrm{PBP}$ matrix, revealing that the sinterability of the matrix is positively correlated with $\mathrm{Cu}$ content and negatively with $\mathrm{Cu}$ particle size [20].

There are three typical features of the hard, dense, weak abrasive rock layer: (1) The rocks are hard and rich in quartz.
(2) The rocks have high strength and is formed by fine minerals; whose particle size mainly falls within $0.01 \sim 0.20 \mathrm{~mm}$. The particles are bonded strongly by siliceous cements, showing a high overall strength. The uniaxial compressive strength is as high as $150 \mathrm{MPa}$. (3) The rocks are weakly abrasive. Due to the lack and fineness of rock powder, the drilling efficiency is low, and the matrix cannot be worn severely, making it difficult to sharpen the diamond.

If applied to a hard, dense, strong abrasive rock layer, the ordinary diamond drill bit is prone to slippage, i.e. the drill bit cannot penetrate the rock or moves at an extremely slow rate of penetration. In this case, the boring schedule will be delayed. To solve this problem, this paper introduces primary and secondary abrasives to improve the drilling efficiency and service life of impregnated diamond drill bit in strong abrasive rock layer, shedding new light on optimizing drill bit performance in such a rock layer.

\section{BIT WEAR MECHANISM WITH PRIMARY AND SECONDARY ABRASIVES}

The wear of diamond drill bit has five modes. (1) Normal wear: The matrix is worn uniformity along the height, the inner diameter and the outer diameter; (2) Process wear: The matrix and diamond are polished; (3) Grinding wear: Grooves appear on the end face, inner surface and outer surface of the matrix; (4) Mechanical wear: The cutting teeth are broken, and the matrix cracks in longitudinal and axial directions; (5) Accidental wear: The matrix suffers from extrusion deformation or micro-burning.

The author applied an ordinary diamond drill bit separately in strong abrasive formations, e.g. sand pebble layer, medium coarse granite layer, concrete layer and relatively broken formation, and observed the crown after the drilling. It is found that the drill bit was worn rapidly along the inner and outer diameters, the working layer at the center of the crown was still high, the two sides of the crown were relatively low, forming a fan-shaped block. In addition, rock powder created grooves on the end face, inner surface and outer surface of the matrix, causing severe grinding wear to these places. The grinding wear is an abnormal wear mode.

In the course of drilling, the matrix of the ordinary drill bit was soon worn out due to the repeated grinding by a large amount of medium and coarse rock powder, losing the ability to hold the diamond in place. Then, the drill bit became less durable or efficient. These defects could be overcome by our diamond drill bit design. If applied to strong abrasive formations, the primary and secondary abrasives of our design can crush the medium and coarse rock powder into finer powder. The fine rock power can be discharged timely and rapidly through the bit end via the drilling fluid.

\section{EXPERIMENT}

\subsection{Drill bit parameters for indoor tests}

Six formulas of primary and secondary abrasives were designed for our tests. The corresponding drill bits were numbered from 1 to 6 . Drill bit \#7, which contains no secondary abrasive, was prepared as the control sample. The samples have the same parameters for the diamond of drill bit, matrix and fabrication technology, and only differ in the 
parameters for the diamond in the secondary abrasive. The drill bit parameters are as follows: outer diameter, 56mm; inner diameter, $39 \mathrm{~mm}$; number of nozzles: 6; height of working layer, $6 \mathrm{~mm}$; matrix hardness, HRC30. The formulas and production parameters are specified in Table 1 . The surface weakening structure of the matrix is shown in Figure 2 .

Table 1. Drill bit formulas and fabrication parameters

\begin{tabular}{|c|c|c|c|c|c|c|}
\hline $\begin{array}{c}\text { Serial } \\
\text { number of } \\
\text { drill bit }\end{array}$ & $\begin{array}{c}\text { Concentration of } \\
\text { secondary abrasive }\end{array}$ & $\begin{array}{c}\text { Particle size of } \\
\text { secondary } \\
\text { abrasive }\end{array}$ & $\begin{array}{c}\text { Matrix } \\
\text { hardness }\end{array}$ & $\begin{array}{c}\text { Parameters of } \\
\text { primary abrasive }\end{array}$ & $\begin{array}{c}\text { Sintering } \\
\text { temperature }\end{array}$ & $\begin{array}{c}\text { Sintering } \\
\text { pressure }\end{array}$ \\
\hline 1 & $2 \%$ & $100 / 120$ meshes & HRC30 & $30 / 40$ meshes & $980^{\circ} \mathrm{C}$ & $5.5 \mathrm{Mpa}$ \\
\hline 2 & $5 \%$ & $100 / 120$ meshes & HRC30 & $30 / 40$ meshes & $980^{\circ} \mathrm{C}$ & $5.5 \mathrm{MPa}$ \\
\hline 3 & $7 \%$ & $100 / 120$ meshes & HRC30 & $30 / 40$ meshes & $980^{\circ} \mathrm{C}$ & $5.5 \mathrm{MPa}$ \\
\hline 4 & $2 \%$ & $120 / 140$ meshes & HRC30 & $30 / 40$ meshes & $980^{\circ} \mathrm{C}$ & $5.5 \mathrm{MPa}$ \\
\hline 5 & $5 \%$ & $120 / 140$ meshes & HRC30 & $30 / 40$ meshes & $980^{\circ} \mathrm{C}$ & $5.5 \mathrm{MPa}$ \\
\hline 6 & $7 \%$ & $120 / 140$ meshes & HRC30 & $30 / 40$ meshes & $980^{\circ} \mathrm{C}$ & $5.5 \mathrm{MPa}$ \\
\hline 7 & - & HRC30 & $30 / 40$ meshes & $980^{\circ} \mathrm{C}$ & $5.5 \mathrm{MPa}$ \\
\hline
\end{tabular}

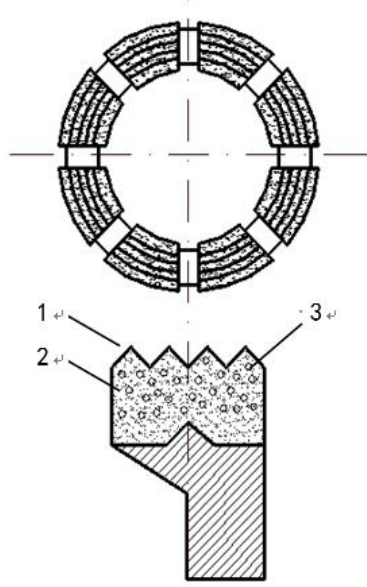

1. Concentric cutting teeth; 2. Diamond particles; 3. Matrix weaken material

Figure 2. The surface weakening structure of the matrix

\subsection{Fabrication technology for indoor test drill bits}

Firstly, the diamond particles and the matrix powder were mixed thoroughly as per design requirements, and then filled into the assembled graphite mold. After that, the non-working layer powder was filled into the mold, and the polycrystalline diamond was placed as required for gauge protection. Finally, the bit body was subjected to hot-press sintering on the assembled graphite mold.

The hot-press sintering includes the following steps: the assembled graphite mold was heated up within the induction coil of an intermediate frequency furnace. An initial pressure was applied after 5 6min of sintering at the heating power of $20 \sim 30 \mathrm{~kW}$. After 8 9min of sintering, the temperature increased to the holding temperature, and full pressure was applied. The temperature was maintained for $5 \mathrm{~min}$ under that pressure. When the temperature dropped to $800^{\circ} \mathrm{C}$, the pressure was removed, and the sintering mold of the drill bit was relocated to an incubator or placed in air to cool down to room temperature [5]. Then, the semi-finished drill bit was demolded and machined. The water system and threads were machined as per the designed sizes.

\subsection{Indoor tests and results analysis}

A batch of concrete bricks $(500 \mathrm{~mm} \times 500 \mathrm{~mm} \times 500 \mathrm{~mm})$ were produced as the drilling objects of the indoor tests. The test rig is a GX-1TD drilling rig produced by CGE (Chongqing) Exploration Machinery Co., Ltd. The drilling pressure was set to $4,800 \mathrm{~N}$, and the rotation speed to $380 \mathrm{r} / \mathrm{min}$. The drilling rig was cooled down with clean water. The drilling time was recorded by a stopwatch. For each drill bit, the height loss was measured by a micrometer, after the bit had drilled 10 holes, and the theoretical service life of the bit was computed. The sharpness of the drill bit was characterized with the time to drill a single hole. The average of the 10 holes was taken as the drilling speed of the drill bit. The test results are listed in Table 2 below.

Table 2. The test results

\begin{tabular}{|c|c|c|c|c|}
\hline $\begin{array}{c}\text { Serial } \\
\text { number } \\
\text { of drill } \\
\text { bit }\end{array}$ & $\begin{array}{c}\text { Number } \\
\text { of holes } \\
\text { (each) }\end{array}$ & $\begin{array}{c}\text { Height } \\
\text { loss } \\
(\mathbf{m m})\end{array}$ & $\begin{array}{c}\text { Mean } \\
\text { drilling } \\
\text { speed } \\
(\mathbf{m} / \mathbf{h})\end{array}$ & $\begin{array}{c}\text { Theoretical } \\
\text { service life } \\
(\mathbf{m})\end{array}$ \\
\hline 1 & 10 & 0.23 & 3.08 & 83 \\
\hline 2 & 10 & 0.16 & 3.15 & 112 \\
\hline 3 & 10 & 0.13 & 3.38 & 155 \\
\hline 4 & 10 & 0.22 & 4.04 & 95 \\
\hline 5 & 10 & 0.17 & 4.16 & 120 \\
\hline 6 & 10 & 0.12 & 4.27 & 160 \\
\hline 7 & 10 & 0.26 & 3.02 & 76 \\
\hline
\end{tabular}

The test results show that the service life and drilling speed of the drill bit changed greatly after proper concentration of secondary abrasive was added. With the particle fineness and drilling speed increased in a certain range, the drill bit saw increasingly significant improvement of its service life and drilling speed.

All drill bits with secondary abrasive had a 10 150\% longer service life than drill bit \#7, which contains no secondary abrasive. The service life was extended because the addition of fine-grained secondary abrasive diamonds reduces the spacing between diamond particles, such that the sand particles (rock powder) larger than the spacing cannot scrape the matrix.

All drill bits with secondary abrasive were 2 40\% more efficient than drill bit \#7, owing to the following reasons. After the addition of secondary abrasive, fine-grained diamonds and coarse-grained diamonds work together, enhancing the cutting effect, and the number of cutting points per unit area of the cutting teeth is increased [6].

Note that the addition of secondary abrasive greatly increased the diamond distribution in the matrix. To crush concrete normally, the drill bit should have a higher axial force 
than the conventional drill bit. With a small axial pressure, the drill bit cannot operate normally.

The above analysis shows that the service life and drilling efficiency of the drill bit on concrete can be improved by adding a proper concentration of micron diamond powder, if particle fineness and drilling speed are within a certain range. The concrete contains lots of sands and gravels and has a high hardness. If their impact speeds relative to the matrix are the same, the sand and gravel particles have a higher momentum than rock powder. During the penetration, the particle size of coarse-grained diamonds will gradually decline when the drill bit faces the sands. After the particle size decreases to a certain threshold, the matrix can no longer hold the diamonds, causing them to fall off. In this case, the fine-grained diamonds, which are widely distributed in the matrix, have a high compressive strength per unit area. If the pressure remains unchanged, the pressure intensity will rise due to the small contact area, the drill bit will be sharpened more easily, fewer areas of the matrix will be exposed, the free surface will widen, and the friction against concrete will growth, laying the basis for efficient crushing of concrete. The collaboration between primary and secondary abrasives speeds up the wear of diamond, and bolsters the drilling efficiency of the drill bit.

In addition, the matrix is worn more severely by the sands and gravels in concrete than rock powder. The addition of micron diamond power increases the number of cutting points per unit of working surface on the crown. Thus, the spacing between diamond particles is shortened. The sand particles larger than the spacing cannot touch the matrix, reducing the matrix wear and improving the drill bit service life [7, 8].

\subsection{Field tests}

The field tests were conducted in a mining area in Shaoyang, central China's Hunan province. The local stratum mainly consists of red glutenite (angular gravels) and medium-grained porphyritic biotite granite (white to grayish white). The drilling parameters include rotation speed, 890 1,180 r/min; drilling pressure, 1,200 kgf. The sulphate emulsified oil was selected as the flushing fluid. The pumping pressure of BW250 mud pump was maintained at 2.0MPa. Four drill bits with primary and secondary abrasives were designed, using the same parameters (Table 3), and compared with a conventional drill bit.

Table 3. Design parameters of field test drill bits

\begin{tabular}{|c|c|c|c|c|c|c|}
\hline $\begin{array}{c}\text { Serial } \\
\text { number of } \\
\text { drill bit }\end{array}$ & $\begin{array}{c}\text { Specification } \\
(\mathbf{m m})\end{array}$ & $\begin{array}{c}\text { Concentration of } \\
\text { secondary abrasive } \\
(\boldsymbol{\%})\end{array}$ & $\begin{array}{c}\text { Particle size of } \\
\text { secondary } \\
\text { abrasive (mesh) }\end{array}$ & $\begin{array}{c}\text { Matrix } \\
\text { hardness } \\
(\text { HRC) }\end{array}$ & $\begin{array}{c}\text { Particle size of } \\
\text { primary } \\
\text { abrasive (mesh) }\end{array}$ & $\begin{array}{c}\text { Concentration of } \\
\text { primary abrasive } \\
(\boldsymbol{\%})\end{array}$ \\
\hline 1 & $\varphi 75 / 49$ & $5 \%$ & $80 / 100$ meshes & 30 & $40 / 50$ meshes & $20 \%$ \\
\hline 2 & $\varphi 75 / 49$ & - & - & 30 & $40 / 50$ meshes & $25 \%$ \\
\hline
\end{tabular}

The field test results (Table 4) show that the drill bits with primary and secondary abrasives had an $85 \%$ higher efficiency and a $46 \%$ longer service life than the conventional drill bit. It can be observed from the used drill bits that the crown of the conventional drill bit suffered from grinding wear, while the drill bits with primary and secondary abrasives did not have that phenomenon.

Table 4. Field test results

\begin{tabular}{|c|c|c|c|}
\hline $\begin{array}{c}\text { Serial number of } \\
\text { drill bit }\end{array}$ & $\begin{array}{c}\text { Number of } \\
\text { cycles }\end{array}$ & $\begin{array}{c}\text { Service } \\
\text { life }(\mathbf{m})\end{array}$ & $\begin{array}{c}\text { Drilling } \\
\text { efficiency } \\
\text { (m/h) }\end{array}$ \\
\hline $\begin{array}{c}\text { Conventional } \\
\text { drill bit }\end{array}$ & 15 & 20.8 & 4.34 \\
\hline 1 & 17 & 30.2 & 8.07 \\
\hline 2 & 16 & 31.6 & 8.03 \\
\hline 3 & 17 & 30.5 & 8.12 \\
\hline 4 & 17 & 31.2 & 8.05 \\
\hline
\end{tabular}

The following is a calculation analysis based on the parameters of the diamond drill bit with primary and secondary abrasives: the drill bit specification is $\varphi 75 / 49 \mathrm{~mm}$ and the pressure on the drill bit is $20 \mathrm{kN}$.

Suppose drill bit A is a conventional drill bit with SMD diamond (particle size: 40/50 meshes; concentration: $25 \%$ ), and drill bit $\mathrm{B}$ is a drill bit with primary abrasive (SMD diamond, particle size: 40/50 meshes; concentration: $20 \%$ ) and secondary abrasive (SMD diamond, particle size: 100/120 meshes; concentration: $5 \%$ ). All the other parameters of the two drill bits are the same. The working layer height of either drill bit was set to $4 \mathrm{~cm}$.

After looking up the available information, the particle size of 40/50 meshes diamond and that of 100/120 meshes diamond are $335 \mu \mathrm{m}$ and $165 \mu \mathrm{m}$, respectively; the diamond density is $3.52 \mathrm{~g} / \mathrm{cm}$; the $\varphi 75 / 49$ drill bit has eight $13 \times 7 \mathrm{~mm}$ water nozzles.

For the $\varphi 75 / 49$ diamond drill bit, the circular crown size, the water nozzle size, the working size and the working layer volume can be respectively computed by:

$$
\begin{gathered}
\mathrm{S}=\pi\left(\mathrm{D}^{2}-\mathrm{d}^{2}\right) / 4=3.14\left(75^{2}-49^{2}\right) / 4=25.30\left(\mathrm{~cm}^{2}\right) \\
\mathrm{Ss}=8 \times 13 \times 7=7.28\left(\mathrm{~cm}^{2}\right) \\
\mathrm{S}_{\mathrm{g}}=\mathrm{S}-\mathrm{S}_{\mathrm{S}}=18.02\left(\mathrm{~cm}^{2}\right) \\
\mathrm{Vg}=\mathrm{Sg} \times \mathrm{H}=18.02 \times 0.4=7.21\left(\mathrm{~cm}^{3}\right)
\end{gathered}
$$

The diamond volume in drill bit $\mathrm{A}$ and in the primary abrasive of drill bit B can be respectively obtained by:

$$
\begin{aligned}
& \mathrm{Vaj}=\mathrm{Ca} \times \mathrm{Vg}=25 \% \times 7.21=1.80\left(\mathrm{~cm}^{3}\right) \\
& V_{b z j}=\mathrm{Cb} \times \mathrm{Vg}=20 \% \times 7.21=1.44\left(\mathrm{~cm}^{3}\right)
\end{aligned}
$$

The volume of each 40/50 meshes diamond can be defined as:

$$
\mathrm{V}_{45}=\pi \mathrm{d}^{3} / 6=0.000010889\left(\mathrm{~cm}^{3}\right)
$$

The number of diamond particles in drill bits $\mathrm{A}$ and $\mathrm{B}$ can be respectively determined by:

$$
\begin{aligned}
& \mathrm{Na}=\mathrm{V}_{\mathrm{aj}} / \mathrm{V} 45=278,897 \text { (particles) } \\
& \mathrm{Na}=\mathrm{V}_{\mathrm{bj}} / \mathrm{V} 45=108,000 \text { (particles) }
\end{aligned}
$$

The number of layers of the working matrix in drill bits $A$ and $\mathrm{B}$ can be respectively determined by: 


$$
\begin{aligned}
& \mathrm{na}=\mathrm{Na}^{-1 / 3}=65 \text { (layers) } \\
& \mathrm{nb}=\mathrm{Nb}^{-1 / 3}=48 \text { (layers) }
\end{aligned}
$$

The areal concentration of diamond in drill bits A and B can be respectively determined by:

$$
\begin{aligned}
& \mathrm{Ma}=\mathrm{Na} / \mathrm{na}=4,290(\text { particles/layer }) \\
& \mathrm{Mb}=\mathrm{Nb} / \mathrm{nb}=2,250 \text { (particles/layer) }
\end{aligned}
$$

The mean pressure of a single diamond on the crown of the working matrix in drill bits $\mathrm{A}$ and $\mathrm{B}$ can be respectively determined by:

$$
\begin{aligned}
& \mathrm{Pa}=\mathrm{P} / \mathrm{Ma}=4.66(\mathrm{~N} / \text { particle }) \\
& \mathrm{Pb}=\mathrm{P} / \mathrm{Mb}=8.89(\mathrm{~N} / \text { particle })
\end{aligned}
$$

The above computations show that the mean pressure of a single diamond on the matrix crown in drill bit B was far greater than that in drill bit $\mathrm{A}$, which promotes the drilling efficiency.

The diamond volume in the secondary abrasive of drill bit B can be computed by:

$$
\mathrm{Vb}_{\mathrm{fj}}=\mathrm{Cb} \times \mathrm{Vg}=5 \% \times 7.21=0.36\left(\mathrm{~cm}^{3}\right)
$$

The volume of each $80 / 100$ meshes diamond can be defined as:

$$
\mathrm{V}_{100}=\pi \mathrm{d}^{3} / 6=0.000002352\left(\mathrm{~cm}^{3}\right)
$$

The number of diamond particles in the secondary abrasive of drill bit B can be determined by:

$$
\mathrm{Na}=\mathrm{V}_{\text {bf. } \mathrm{j}} / \mathrm{V}_{80}=306,547 \text { (particles) }
$$

The total areal concentration of diamond in primary and secondary abrasives of drill bit $\mathrm{B}$ can be determined by:

$$
\mathrm{M}=\mathrm{Mb}+\mathrm{Mbf}=8,636 \text { (particles/layer) }
$$

The areal concentration of diamond in drill bit A can be determined by:

$$
\mathrm{Ma}=\mathrm{Na} / \mathrm{na}=4,290 \text { (particles/layer) }
$$

The above calculations show that the total areal concentration of diamond in primary and secondary abrasives of drill bit B was twice that of the areal concentration of diamond in drill bit $\mathrm{A}$. The relatively large areal concentration means a small spacing between diamond particles, which reduces the matrix wear by coarse rock powder. This phenomenon contributes to the crushing effect of the diamond drill bit with primary and secondary abrasives over rocks, and promotes the service life of the drill bit. To sum up, the collaboration between primary and secondary abrasives helps to improve the service life and drilling efficiency of drill bit.

\section{CONCLUSIONS}

(1) The plan of primary and secondary abrasives, targeted at strong abrasive rock layer, is feasible and significant both practically and theoretically.

(2) The theory of primary and secondary abrasives was integrated into the drill bit design. The resulting design enhances the drilling efficiency of impregnated diamond drill bit without shortening its service life. The drill bits with primary and secondary abrasives had an $85 \%$ higher efficiency and a $46 \%$ longer service life than the conventional drill bit.

(3) In the course of drilling, the matrix of the ordinary drill bit was soon worn out due to the repeated grinding by a large amount of medium and coarse rock powder, losing the ability to hold the diamond in place. Then, the drill bit became less durable or efficient. These defects could be overcome by our diamond drill bit design. If applied to strong abrasive formations, the primary and secondary abrasives of our design can crush the medium and coarse rock powder into finer powder. The fine rock power can be discharged timely and rapidly through the bit end via the drilling fluid.

\section{REFERENCES}

[1] Nouveau, A. (2013). Cobalt power used for diamond tools. 6th Zhengzhou International Superhard Materials and Related Products Conference Proceedings, pp. 128130.

[2] Wang, J.L., Zhang, S.H., Peng, F.F. (2018). Influence mechanism of hard brittle grits on the drilling performance of diamond bit. Annales de Chimie Science des Matériaux, 42(2): 209-220. https://doi.org/10.3166/ACSM.42.209-220

[3] de Oliveira, L.J., Bobrovnitchii, G., Filgueira, M. (2007). Processing and characterization of impregnated diamond cutting tools using a ferrous metal matrix. International Journal of Refractory Metals and Hard Materials, 25(2): 328-335. https://doi.org/10.1016/j.ijrmhm.2006.08.006

[4] del Villar, M., Muro, P., Sanchez, J.M., Iturriza, I. (2014). Consolidation of diamond tools using $\mathrm{Cu}-\mathrm{Co}-\mathrm{Fe}$ based alloys as metallic binders. Powder Metallurgy, 44(1): 8290. https://doi.org/10.1179/003258901666211

[5] Thorat, R.R., Brahmankar, P.K., Mohan, T.R.R. (2004). Consolidation behavior of $\mathrm{Cu}-\mathrm{Co}-\mathrm{Fe}$ pre-alloyed powders. Inter-national Symposium of Research Students on Materials Science and Engineering, 22: 1-6. http://www.doc88.com/p-802803397318.html

[6] Ding, H.D., Li, Y.W., Yang, X.H., Hao, H.Q., Jin, Z.H. (1998). Design of a non-homo geneous diamond bit matrix. Journal of Materials Processing Technology, 84(2): 159-161. https://doi.org/10.1016/S09240136(98)00092-2

[7] Tan, S.C., Fang, X.H., Yang, K.H., Duan, L.C. (2014). A new composite impregnated diamond bit for extra-hard, compact, and nonabrasive rock formation. International Journal of Refractory Metals and Hard Materials, 43(3): 186-192. https://doi.org/10.1016/j.ijrmhm.2013.11.001

[8] Chern, B., Ozgur, A. (2012). Achieving the capacity of the N-Relay gaussian diamond network within $\log \mathrm{N}$ bits. IEEE Transactions on Information Theory, 60(12): 377380. https://doi.org/10.1109/ITW.2012.6404697

[9] ARIX. (2005). A revolution in the diamond tool industry. The Korea Post News and Business, 17(3): 125-127.

[10] Jia, M.L., Cai, J.P., Ouyang, Z.Y., Shen, L.N., Wu, H.X., Li, C. (2014). Design and application of diamond bit to 
drilling hard rock in deep borehole. 2014 International (China) Geological Engineering Drilling Technology Conference, 73, pp. 134-142. https://doi.org/10.1016/j.proeng.2014.06.181

[11] Cheng, W.G. (2011). Discussion on the properties of matrix alloys for hot pressed sintered diamond tools. National Symposium on Powder Metallurgy and CrossStrait Symposium on Powder Metallurgy Technology.

[12] Xun, L., Sun, Y.H. (2008). Efficient rock fragmentation mechanism analysis of impregnated diamond bionics bit. Journal of Jinlin University, 38(6): 1015-1019. https://doi.org/10.1002/clen.200700058

[13] Brookes, K.J.A. (2000). Inside Boart Longyear's hard materials facilities. Metal Powder Report, 55(11): 36-41. https://doi.org/10.1016/S0026-0657(00)80104-6

[14] Mattias, O. (2013). Edwards shareholders approve acquisition by Atlas Copco. Pump Industry Analyst, (10): 12-12. https://doi.org/10.1016/S1359-6128(13)70400-2

[15] Burr R. (2000). OUT Success stories: diamond-cutter drill bits. National Renewable Energy Laboratory, Golden, CO (US).

[16] Papaxoinis G, Papageorgiou S D, Kaloutsi V, Fountzilas, G., Pavlidis, N., Dimopoulos, M., Tsatalas, C., Xiros, N., Economopoulos, T. (2006). Primary gastrointestinal
non-Hodgkin's lymphoma: A clinicopathologic study of 128 cases in Greece. A Hellenic Cooperative Oncology Group Study (HeCOG). Leukemia \& Lymphoma, 47(10): 2140-2146. https://doi.org/10.1007/BF02829250

[17] Franks, J., Rogers, K., Guimond, Y. (2008). Optical and thermo-mechanical properties of infrared glasses. Spie Defense \& Security Symposium, (6940): 22-22. https://doi.org/10.1117/12.779706

[18] Chalus, P.A.D. (1998). Eurotungstene introduces the NEXT step. Metal Powder Report, 53(3): 22, 24-25. https://doi.org/10.1016/S0026-0657(97)89642-7

[19] Papezik, V.S. Barr, S. (2011). The Shelburne dike, an early Mesozoic diabase dike in Nova Scotia: Mineralogy, chemistry, and regional significance: Reply. Canadian Journal of Earth Sciences, 18(8): 1346-1355. https://doi.org/10.1139/e81-124

[20] Villar, M.A.E.D. (2011). Lengua, identidad y medios de comunicación en la comunidad chicana / M.A. Echegaray del Villar. Anuari Verdaguer, 39(4): 177-205.

[21] Thorat, R.R., Risanti, D.D., Martín, D.S., Garces, G. (2009). On the transformation behaviour of NiTi particulate reinforced AA2124 composites. Journal of Alloys \& Compounds, 477(1): 307-315. https://doi.org/10.1016/j.jallcom.2008.11.002 